
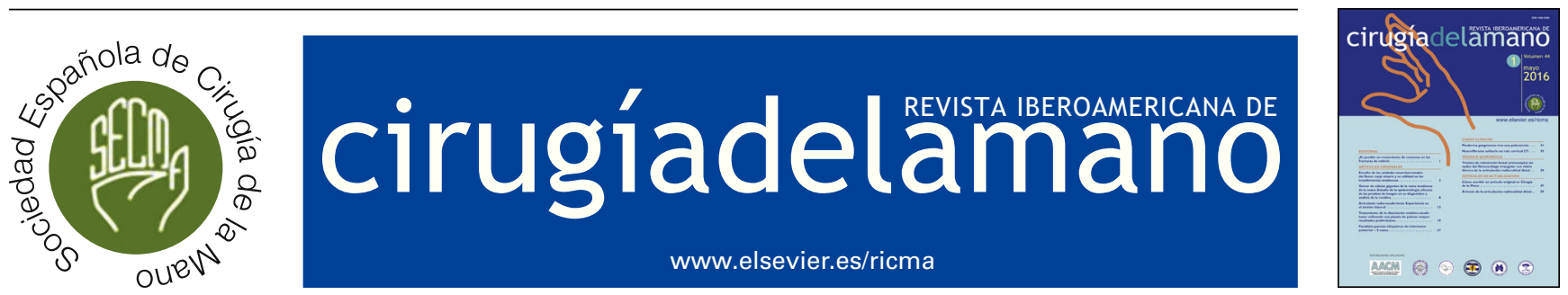

FE DE ERRORES

\title{
Fe de errores de "Fracturas del radio distal: encuesta sobre preferencias de manejo y tratamiento"
}

\section{Erratum to 'Distal radius fractures: Survey of management and treatment preferences'}

\section{P.J. Delgado ${ }^{\mathrm{a}, *}$, D.M. Martínez-Capoccioni ${ }^{\mathrm{b}}$ y J. Cervera ${ }^{\mathrm{c}}$}

a Unidad de Cirugía de la Mano y del Miembro Superior, Hospital Universitario Madrid Montepríncipe, Universidad CEU San Pablo, Boadilla del Monte, Madrid, España

b Servicio de Cirugía Ortopédica y Traumatología, Hospital Povisa, Vigo, España

c Servicio de Cirugía Ortopédica y Traumatología, Hospital General de Villalba, Collado Villalba, Madrid, España

En el artículo "Fracturas del radio distal: encuesta sobre preferencias de manejo y tratamiento" (Rev Iberoam Cir Mano. 2015;43:28-37) de P.J. Delgado et al., se ha detectado un error en el nombre de uno de los autores. El nombre correcto es: D.M. Martínez-Capoccioni.

Véase contenido relacionado en DOI: http://dx.doi.org/10.1016/j.ricma.2015.06.006

* Autor para correspondencia.

Correo electrónico: pedrojdelgado@me.com (P.J. Delgado). 